\title{
The Realization of Mood through Lexical Choices in English Public Service Advertising Texts
}

\author{
Yanqing Fang \\ Department of Foreign languages, Xiamen University Tan Kah Kee College, Xiamen, China
}

247682022@qq.com

Keywords: Mood system; English public service advertising; Lexical choices

\begin{abstract}
Public service advertisement can indicate the relationship between the advertiser and the audience as well as the interaction and negotiation between them. Based on the systemic functional grammar, this research aims to investigate the interpersonal meaning of mood system through lexical choices. Modal operators and mood adjuncts are frequently used to realize mood, while the advertiser applies few comment adjuncts to the public service advertising texts. Positive modal operators are much more than negative modal operators. More frequent occurrence of positive low and median modal operators indicates the speaker wants the listener to believe in the truthfulness of his meanings, positiveness of his attitudes, feelings and actions in the public service advertising. Moreover, most of the high modal operators are used to express the audience's incapability of doing something.
\end{abstract}

\section{Introduction}

Advertisements can mainly be classified into two types: commercial advertisement and non-commercial advertisement. Scholars have analyzed commercial advertisement discourse from different aspects. However, with the rapid growth of economy, some serious social problems, for instance, pollution, AIDS, poverty, drug abuse have great negative influences on the development of the society. Public service advertisements aim to inform the public of those important social issues and problems, to attract people's attention on these things and stimulate their positive action to take part in the campaign to solve these significant issues. Public service advertisement is the medium between the advertiser and the audience; it can indicate the relationship between the advertiser and the audience as well as the interaction and negotiation between them. Therefore, it is meaningful to do research on how the advertiser builds relationship with the audience and how the advertiser persuades the audience to take positive action through a variety of linguistic strategies. The American public service advertising originated from the year 1941. In consideration of the fact, that the United States is the pioneer in the development of public service advertising. The research chooses the English public service advertising texts issued by the United States as the target research discourses. Based on the systemic functional grammar, this thesis aims to investigate the interpersonal meaning of mood system in English public service advertising texts. It will do research on how the advertiser builds the relationship with the audience and how the advertiser persuades the audience to take positive actions through the application of mood system through lexical choices.

Halliday is the initiator of Systemic Functional Grammar (SFG), and SFG plays a very important role in various discourse analyses. Halliday's interpersonal function is the function of interaction of people. Halliday [4] developed Functional Grammar for people who study grammar for the purpose of text analysis. This kind of text analysis focuses on the study of various meanings realized by various language structures as well as the different functions of language. Mood system, as a way of realizing interpersonal meaning, is a great tool to analyze discourses. Halliday [4] points out that interpersonal function can be realized by lexico-grammatical system and phonological system: mood, modality and key. Mood system plays an important role in the realization of interpersonal function and many scholars in and out of China do researches on it. Based on the systemic functional grammar, this thesis aims to investigate the interpersonal meaning of mood system 
through lexical choices in English public service advertising texts. The research randomly selects 35 samples from the English public service advertisements issued by the American government on the internet. It may help the advertisers or students in China to learn some valuable insights and help them to create better public service advertisements. It may also enrich the studies of advertising discourse and attract more scholars to do researches on this kind of discourse through different perspectives. Moreover, this research may help understand why and how different mood systems are used for particular purpose. This will help the student to learn more about the relationship between communicative purposes and linguistic features.

\section{Literature Review}

\section{Studies on Mood System in Various Discourse Types}

In daily life, people use language to communicate with each other. People use language to exchange meanings; provide information and influence other's attitude, behavior. This function of language is called interpersonal function. Mood system, as one way of expressing interpersonal meaning, is one of the important parts in Halliday's Systemic Functional Grammar (SFG). SFG considers language as a social semiotics, which is a resource people use to accomplish their purposes by expressing meaning in context. Halliday [3] studies the development of dialogue and the mood system in young children's language. Thompson and Thetela [9] summarize three grammatical systems (mood, modality and evaluation) in realizing interpersonal meaning. Many Chinese scholars have also done researches on the theory of mood. Li Zhanzi [6] exploits the realization of interpersonal meaning in academic discourses and autobiographies. Meanwhile, the realization of interpersonal functions of mood is also widely used in the analysis of advertisement discourse in China. Zhu Hongtao [10] analyzes the person and mood system in English advertising discourse and concludes that the person and mood system in English advertising discourse are means of manipulation of the reader. Scholars have done a lot of researches on mood system in different discourses, including some advertisements, but rarely for public service advertisements. However, the language study of public service advertisement is popular.

\section{Studies on Public Service Advertisement Texts}

Advertising, as a special discourse, has always attracted a lot of attention from linguistic scholars in and out of China. Many scholars have explored advertising discourse, such as Cook [1] and Huang Guowen [5]. Their researches have great extent and profundity, so they are very useful to the other researchers. However, they pay comparatively less attention to the public service advertising texts, so there is wide space for the research on the characteristics of public service advertising texts. The purpose of public service advertising is releasing government policies, promoting desirable lifestyle and high moral standard and appealing to the public to offer help to victims in disasters. In general, it is a discourse with persuasive intent, aiming at instilling thoughts in the public. Moreover, researches on public service advertising texts in China are mainly from the perspectives of sociology and aesthetics. Sun Ran [7] tentatively analyzes an English public service advertising text published on Fortune. Chen Linlin [2] studies the interpersonal meanings in the discourse of public service advertising. As it is shown on the above researches, the authors seldom pay special attention to the mood system and its interpersonal meanings in public service advertising texts. Thus, the present research attempts to explore the interpersonal meaning of public service advertising texts through lexical choices and hopefully it may enrich studies on this particular area. While, before we carry out this analysis, it is necessary to introduce the theoretical framework of this study. In what follows, theoretical framework of the present research is surveyed.

\section{Theoretical Framework of Mood System}

\section{Mood System}

People use language to exchange meanings, to express ideas, and influence others' attitude, behavior, to establish and maintain relationship with them. Th2 function of language is called the interpersonal function. As one of the three metafunctions, Halliday [4] points out that the 
interpersonal function can be realized by lexico-grammatical system and phonological system: mood, modality and key. Mood represents interpersonal functions through the following ways: the interaction between the speaker and reader in discourse and the speaker's attitude to what he speaks or writes.

\section{The Realization of Mood through Different Lexical Choices}

The realization of mood at lexical level is done by Modal Operators and Modal Adjuncts, which include Mood Adjuncts and Comment Adjuncts.

\section{Modal Operators}

According to Halliday [4], modal operators correspond both to mood and to modality. It can be used to realize the function of expressing probability and usuality of modalization, as well as the obligation and inclination of modulation. However, in mood system, it refers to the finite elements. Finite has the function of making the proposition relate to its context in the speech event. This can be achieved in two ways: one is by reference to the time of speaking; the other is by reference to the judgment of the speaker. The two ways are tense and modality as it is mentioned before. In functional linguistics, modal operator can be called modal auxiliary. It is related to the different ways by which the speaker expresses his opinion or attitude about the validity of what he or she says. In other words, what the speaker says includes the speaker's judgment of probabilities, or the obligations. Halliday [4] classified modal operators into three subcategories: the low, median and high degrees of mood to realize interpersonal meanings.

Table 1 Modal Operators

\begin{tabular}{|c|c|c|c|}
\hline Positive & $\begin{array}{c}\text { Low } \\
\text { Can, may, could, might, } \\
\text { dare }\end{array}$ & $\begin{array}{c}\text { Will, would, should, is } \\
\text { / was to }\end{array}$ & $\begin{array}{c}\text { Must, ought to, need, has / have } \\
\text { to }\end{array}$ \\
\hline Negative & $\begin{array}{c}\text { Needn't, have to } \\
\text { doesn't/didn't need to },\end{array}$ & $\begin{array}{c}\text { Won't, wouldn't, } \\
\text { shouldn't, (isn't / } \\
\text { wasn't) }\end{array}$ & $\begin{array}{c}\text { Mustn't, oughtn't to, can't, } \\
\text { couldn't, (mayn't, mightn't, } \\
\text { hasn't / hadn't to) }\end{array}$ \\
\hline
\end{tabular}

\section{Modal Adjuncts}

The other part of realizing mood at lexical level lies in modal adjuncts, which play an important role in the clause. Modal adjuncts add meanings to the mood element, which relates to the speaker's evaluation or judgment or to the polarity (positive or negative) of the finite element. Modal adjuncts mainly consist of two interpersonal types: mood adjuncts and comment adjuncts. Mood adjuncts are frequently used in English to modify the speaker's commitment to the factuality of his statement. They are closely associated with the meanings construed in the mood system. They carry interpersonal functions and express provability, intensification or minimization, obligation, inclinations and usuality.

According to Halliday ([4]: 82-83) mood adjuncts include the following elements:

Table 2 Mood Adjuncts

\begin{tabular}{|c|c|c|}
\hline \multirow{5}{*}{$\begin{array}{l}\text { Adjuncts of polarity and } \\
\text { modality }\end{array}$} & Polarity & not, yes, no, so \\
\hline & Probability & probably, possibly, certainly, perhaps, maybe \\
\hline & Usuality & usually, sometimes, always, never, ever, seldom, rarely \\
\hline & Readiness & willingly, readily, gladly, certainly, easily \\
\hline & Obligation & definitely, absolutely, possibly, at all costs, by all means \\
\hline \multirow{2}{*}{$\begin{array}{l}\text { Adjuncts of } \\
\text { temporality }\end{array}$} & Time & yet, still, already, once, soon, just \\
\hline & Typicality & occasionally, generally, regularly, mainly, for the most part \\
\hline \multirow{3}{*}{ Adjuncts of mood } & Obviousness & of course, surely, obviously, clearly \\
\hline & Intensity & just, simply, merely, only, even, actually, really, in fact \\
\hline & Degree & $\begin{array}{c}\text { quite, almost, nearly, scarcely, hardly, absolutely, totally, utterly, } \\
\text { entirely, completely. }\end{array}$ \\
\hline
\end{tabular}


Comment adjuncts express the speaker's attitude to the proposition. In addition, there is no clear difference between Comment Adjuncts and Mood Adjuncts. Compared to Mood Adjuncts, Comment Adjuncts are less integrated into the clause's mood structure. Comment adjuncts are the reflections of the speaker's opinion toward what he says. The items that function as Comment Adjuncts are summarized by Halliday ([4]: 49). Comment adjuncts can be categorized base on their semantic distinctions.

Table 3 Comment Adjuncts

\begin{tabular}{|c|c|}
\hline Opinion & in my opinion, personally, to my mind \\
\hline Admission & frankly, to be honest, to tell you the truth \\
\hline Persuasion & honestly, really, believe me, seriously \\
\hline Entreaty & please, kindly \\
\hline Presumption & evidently, apparently, no doubt, presumably \\
\hline Desirability & $\begin{array}{l}\text { (un) fortunately, to my delight/distress, regrettably, } \\
\text { hopefully }\end{array}$ \\
\hline Reservation & at first, tentatively, provisionally, looking back on it \\
\hline Validation & $\begin{array}{l}\text { broadly speaking, in general, on the whole, strictly } \\
\text { speaking, in principle }\end{array}$ \\
\hline Evaluation & (un) wisely, understandably, mistakenly, foolishly \\
\hline Prediction & to my surprise, surprisingly, as expected, by chance \\
\hline
\end{tabular}

\section{Research Methodology}

Data Collection. The present research is carried out basing on a corpus of 35 public service advertising texts collected from the internet. These texts are published by the influential organizations, such as the American Red Cross, American Cancer Society, My Wonderful World Organization and Common Sense for Drug Policy, etc. The data can be characterized by the following features. First, it represents contemporary American advertising language. All samples are randomly selected from the internet. Second, all texts included in our data are complete advertisements and unmodified. Third, the texts identify a wide range of significant public issues, ranging from natural disaster to language study to the protection of wildlife.

Research Methods. Quantitative analyses are made in the course of exploration of interpersonal function in terms of mood system. In the research, the author tries to make statistical analyses to explore the interpersonal functions of mood system in public service advertising.

The Realization of Mood through Lexical Choices in PSA

The realization of mood through different lexical choices is realized by Modal Operators and Modal Adjuncts, which include Mood Adjuncts and Comment Adjuncts. There are some characteristics of the distribution of mood at the lexical level in public service advertising. See Table 4

Table 4 Realization of Mood through Different Lexical Choices

\begin{tabular}{|c|c|c|c|c|}
\hline Mood element & $\begin{array}{c}\text { Modal } \\
\text { Operators }\end{array}$ & Mood Adjuncts & $\begin{array}{c}\text { Comment } \\
\text { Adjuncts }\end{array}$ & Total \\
\hline Frequency & 56 & 85 & 6 & 147 \\
\hline Percentage & $38.1 \%$ & $57.8 \%$ & $4.1 \%$ & $100 \%$ \\
\hline
\end{tabular}

Table 4 lists the occurrence of all the modal operators, mood adjuncts and comment adjuncts. It shows that speakers use the comparatively high frequency of modal operators (56) and mood adjuncts (85) to realize mood. At the same time, they apply few comment adjuncts (6) to the public service advertising texts. 


\section{Modal Operators}

Modal operators consist of positive modal operators and negative operators. Each pattern of modal operator has the three degrees: low, median, and high. In this section, the research will illustrate the distribution of modal operators used in the public service advertising texts selected.

Table 5 Modal Operators

\begin{tabular}{|c|c|c|c|c|c|c|c|c|c|c|c|c|c|}
\hline \multirow{3}{*}{$\begin{array}{l}\text { Modal } \\
\text { Operators }\end{array}$} & \multicolumn{9}{|c|}{ Positive } & \multicolumn{4}{|c|}{ Negative } \\
\hline & \multicolumn{4}{|c|}{ Low } & \multicolumn{3}{|c|}{ Median } & \multicolumn{2}{|l|}{ High } & \multirow{2}{*}{$\begin{array}{l}\text { Low } \\
\text { Don't } \\
\text { have to }\end{array}$} & \multirow{2}{*}{$\begin{array}{l}\text { Median } \\
\text { Won't }\end{array}$} & \multicolumn{2}{|l|}{ High } \\
\hline & can & may & might & could & will & would & should & need & Have to & & & Can't & $\begin{array}{l}\text { May } \\
\text { not }\end{array}$ \\
\hline Frequency & 16 & 1 & 1 & 5 & 13 & 8 & 1 & 1 & 2 & 1 & 2 & 4 & 1 \\
\hline Total 1 & \multicolumn{4}{|l|}{23} & \multicolumn{3}{|l|}{22} & \multicolumn{2}{|l|}{3} & 1 & 2 & \multicolumn{2}{|l|}{5} \\
\hline Total 2 & \multicolumn{9}{|l|}{48} & \multicolumn{4}{|l|}{8} \\
\hline Total 3 & 56 & & & & & & & & & & & & \\
\hline
\end{tabular}

The results of the frequency analysis of modal operators show that positive value modal operators are used most frequently. Positive modal operators account for 48 while negative modal operators only 8. Among the positive modal operators as well as all the modal operators in this table, the positive low ones rank first. Following it, the median positive modal operators have 22 modal operators. Then the negative high modal operators rank the third on the table. Among all the operators as shown in table 5, can (16), will (13), would (8) and can't (4) occur comparatively frequently in the texts.

As it is mentioned above, modal operator shows the validity of what the speaker has said. More frequent occurrence of positive low and median modal operators indicates the speaker wants the listener to believe in the truthfulness of his meanings, positiveness of his attitudes, feelings and actions in the public service advertising. Though the statistics show the positiveness of mood, the speaker does not impose heavily on the reader. With low and median positive modal operator, the speaker makes the interaction negotiable in the exchange of meanings. Moreover, most of the high modal operators are used to express the audience's incapability of doing something. Then this is the matting for the advertiser to tell the audience what to do in the following part. For example:

Example ( 1 )

(1) Half of American's youth can't find countries such as Japan, India and Iraq on a map-places essential to understand in a globally connected world. (NO.9)

(2) you can't stop a hurricane.

you can't predict an earthquake.

you can't control a thunderstorm. (NO.18)

Among these modal operators, "can" reaches the frequency of 16 of the modal operators, which is the highest one among all the modal operators. Possibility and ability can be expressed by "can". In addition, possibility and ability can help the audiences to have the belief that if they do as what the public service advertiser tells them to, then they may be able to or it is possible for them to do the following good things. See example 2:

\section{Example (2)}

That's what learning another language can do for your child. (NO.1)

So they can communicate, understand others and compete in a global environment. (NO.3)

Today we can see bald eagles in the wild - California condors, grizzly bears, and humpback whales, too. (NO.8)

The way he can hear the ice cream man four blocks away. (NO.12)

How he always sends the flowers to the office so everyone can see. (NO.14)

Pick a place where family members can gather in a disaster (NO.22)

The advertiser frequently uses "can" in public service advertising texts, but he leaves the decisions of showing ability to the audience. The advertiser let the audiences think whether they 
have the ability to do so and whether they want to do so. It is more interactive and communicative between the participants.

Following "can", "will" ranks the second of the modal operators. "Will" with the subjective implicit orientation carry positive median value. "Will" is not a logical inference process, but expresses a high degree of predicative certainty of attitudes, actions or behaviors. See Example 3:

Example (3)

That means bald eagles, grizzly bears, California condors, and sea otters will be around for future generations to enjoy (NO.4)

More importantly, these magnificent creatures will be around for our children and grandchildren to enjoy. (NO.8)

Not only will you be funding yourself, you'll also be helping to be helping to feed others. (NO.33)

And, like last year $70 \%$ of the proceeds will stay right here in Jackson, benefiting Stewpot Community Services. (NO.35)

By using "will", the speaker is confident of bringing the listener to believe in his statements. The sentence lead by "will" in fact is a promise made by the advertiser to let the audience trust him and therefore do actions as the advertiser says.

\section{Modal Adjuncts}

The other part of the realization of mood through different lexical choices is through Modal Adjuncts which includes mood adjuncts and comment adjuncts. The distribution of mood adjuncts and comment adjuncts is illustrated as follows:

Table 6 Mood Adjuncts

\begin{tabular}{|c|c|c|c|c|c|}
\hline \multirow{2}{*}{ Mood Adjuncts } & \multicolumn{2}{|c|}{$\begin{array}{c}\text { Adjuncts of Polarity and } \\
\text { Modality }\end{array}$} & Adjuncts of Temporality & \multicolumn{2}{c|}{ Adjuncts of Mood } \\
\cline { 2 - 6 } & Polarity & Usuallity & Time & Intensity & Degree \\
\hline Frequency & 51 & 11 & 7 & 12 & 4 \\
\hline Total 1 & \multicolumn{2}{|c|}{62} & 7 & 16 \\
\hline Total 2 & \multicolumn{2}{|c}{85} & \multicolumn{2}{c}{} \\
\hline
\end{tabular}

Mood adjuncts rank the first place in the use of modal adjuncts in public service advertising. The above Table 6 shows the specific distribution of different kinds of Mood Adjuncts. As it is shown in Table 6, among the 85 mood adjuncts in the public service advertising text selected, adjuncts of polarity and modality (62) rank the first place, the second place is the adjuncts of mood, and the last on is the adjuncts of temporality. In the following parts, the author will make further analysis of the three parts of mood adjuncts. See Table7, Table 8, and Table 9:

Table 7 Adjuncts of Polarity and Modality

\begin{tabular}{|c|c|c|c|c|c|}
\hline \multirow{2}{*}{ P \&M } & \multicolumn{2}{|c|}{ Polarity } & \multicolumn{3}{c|}{ Usuallity } \\
\cline { 2 - 6 } & Yes & Not/ no & always & never & ever \\
\hline Frequency & 33 & 18 & 3 & 7 & 1 \\
\hline Total 1 & \multicolumn{2}{|c|}{51} & \multicolumn{2}{c|}{62} \\
\hline Total 2 & \multicolumn{5}{|c|}{62} \\
\hline
\end{tabular}

With comparatively high frequency of adjuncts of polarity (yes) (33), (no/not) (18) and usuallity (never) (7), the advertiser expresses his meanings without fuzzy and vague ideas. He wants the audience to think about how confirmable of his statement or command is. See Example 4:

Example (4):

We are not alone. (NO.9)

Never leave burning candles unattended. (NO.19) 
With the American Red Cross, You're Never Out of Touch. (NO.28)

Table 8 Adjuncts of Temporality

\begin{tabular}{|c|c|c|c|c|}
\hline \multirow{2}{*}{ Temporality } & \multicolumn{4}{|c|}{ Time } \\
\cline { 2 - 5 } & yet & still & once & just \\
\hline Frequency & 1 & 1 & 4 & 1 \\
\hline Total & \multicolumn{5}{|c|}{7} \\
\hline
\end{tabular}

Public service advertising texts use few adjuncts of temporality. Compared with other adjuncts of temporality, "once" ranks high with four times of occurrence in public service advertising. "Once" represents the serious consequences that caused by the human being's destructive activities. This can attract the audience attention, affect their behavior, and thus encourage them to take positive action to protect the nature. For example, "AMERICA'S NATIONAL SYMBOL was once almost lost forever." (NO.8)

Table 9 Adjuncts of Mood

\begin{tabular}{|c|c|c|c|c|c|c|c|}
\hline \multirow{2}{*}{$\begin{array}{c}\text { Adjuncts of } \\
\text { mood }\end{array}$} & \multicolumn{4}{|c|}{ Intensity } & \multicolumn{5}{c|}{ Degree } \\
\cline { 2 - 8 } & just & only & even & quite & completely & nearly & almost \\
\hline Frequency & 3 & 5 & 4 & 1 & 1 & 1 & 1 \\
\hline Total 1 & \multicolumn{3}{|c|}{12} & \multicolumn{5}{|c|}{4} \\
\hline Total 2 & 12 & \multicolumn{7}{c}{} \\
\hline
\end{tabular}

As for the Adjuncts of Mood, adjuncts that represent Intensity are much more than the adjuncts that represent Degree. Among the adjuncts of mood, the word "just" ranks comparatively high in the public service advertising texts. For instance, "Just one donation can help save up to three lives." (NO.28) The word "just" emphasize that the audience only have to do some little easy things, but this can give great help to the others who are in trouble. This is an obvious contrast-little thing causes big effect. Thus, this can encourage the audience to take positive actions to help the people who are in trouble.

The other part of the Modal Adjuncts is the Comment Adjuncts, which express the speaker's attitude towards the proposition. The following part will show the distribution of comment adjuncts in public service advertising texts selected in this research. See Table 10:

Table 10 Comment Adjuncts

\begin{tabular}{|c|c|c|c|c|}
\hline $\begin{array}{c}\text { Comment } \\
\text { Adjuncts }\end{array}$ & please & $\begin{array}{c}\text { more } \\
\text { importantly }\end{array}$ & sadly & sure \\
\hline Frequency & 2 & 1 & 2 & 1 \\
\hline Total & \multicolumn{2}{|r}{} \\
\hline
\end{tabular}

The above Table 10 shows that comment adjuncts are not frequently used in public service advertising texts. Comment adjuncts express the speakers' attitude, evaluation or opinion, etc. only six comment adjuncts are found in the texts. The word "please" expresses politeness or mitigation of command. "Please" often precedes imperatives to mitigate the command by use of it. See Example 5:

Example (5):

Please join me and become one of the one million American Red Cross volunteers in the United States. (NO.24)

For more information about our military services, please call your local American Red Cross chapter... (NO.29)

In Example 5, although these are the advertiser's commands for the audience, the advertiser uses the word "please" at the beginning of the imperatives. This can make the command more polite and the relationship between the advertiser and the audience more intimate. By doing this, the audience 
would be more likely to accept the command and take the positive action to join or call the American Red Cross.

\section{Summary}

Modal operators and mood adjuncts are frequently used to realize mood, while the advertiser applies few comment adjuncts to the public service advertising texts. Positive modal operators are much more than negative modal operators are. More frequent occurrence of positive low and median modal operators indicates the speaker wants the listener to believe in the truthfulness of his meanings, positiveness of his attitudes, feelings and actions in the public service advertising. Moreover, most of the high modal operators are used to express the audience's incapability of doing something. Among these modal operators, "can" and "will" are most frequently used to make the audience believe what the advertiser says and therefore take actions as the advertiser says.

As for modal adjuncts, which consist of mood adjuncts and comment adjuncts, mood adjuncts are frequently used while comment adjuncts are seldom used in public service advertising texts. Among the mood adjuncts, adjuncts of polarity and modality rank the first place because the advertiser wants to express his meanings without fuzzy and vague ideas. As for adjuncts of temporality, the word "once" is comparatively frequently used to represent the serious consequences that caused by the human being's destructive activities. For the adjuncts of mood, "just" is used to make obvious contrast- little thing causes big effect. In the analysis of comment adjuncts, "please" can express politeness or mitigation of command.

\section{References}

[1] Cook, G, The Discourse of Advertising, 221, London: Routledge, 2003.

[2] Chen Linlin, Interpersonal Meanings in the Discourse of Public Service Advertising, Qingdao: Shandong University Press, 2007.

[3] Halliday, M. A. K, An Introduction to Functional Grammar, London: Edward Arnold, 1985.

[4] Halliday, M.A.K, An Introduction to Functional Grammar. London: Edward Arnold, 1994.

[5] Huang Guowen, Theory and Practice of Discoures Analysis-A Study on Advertisement Discourse, Shanghai:Shanghai Foreign Language Education Press, 2001.

[6] Li Zhanzi, Interpersonal Meaning in Discourse, Beijing: Yi Wen Publishing Military, 2002.

[7] Sun Ran, A Tentative Analysis of Public Service Advertising Discourse, Shandong Foreign Language Teaching Journal, 2004, (6).

[8] Thibault, The Interpersonal Enactment of Agency: Towards a social Motivated Account of the Interpersonal Grammar of Mood in English, Semiotically NENU, 2004.

[9] Thompson, G., \& P. Thetela, The Sound of One Hand Clapping: the management of interaction in written discourse, text 15 (1), 103-127,1995.

[10] Zhu Hongtao. Interpersonal Functions of Person and Mood in English Advertising Discourse, Shandong Foreign Language Teaching Journal, 2003, (2). 